\title{
Community-Based Advanced Practice Nursing (APN): The Road to Vision 2020
}

\author{
Nerminathan Veerasingam, Mustafa Al-Musawi, Presena Selvarajah \\ Monash University Malaysia, Johor Bahru, Malaysia \\ Email: nerminathan.veerasingam@monash.edu
}

Received 24 April 2016; accepted 8 May 2016; published 12 May 2016

Copyright (C) 2016 by authors and OALib.

This work is licensed under the Creative Commons Attribution International License (CC BY). http://creativecommons.org/licenses/by/4.0/

(c) $\underset{\mathrm{EY}}{\mathrm{B}}$ Open Access

\section{Abstract}

Malaysia is a heterogenous, multi-ethnic society with a population of 30 million, of which $74 \%$ reside in urban areas. Since gaining independence, the main priority of health policy makers is to provide and enhance the delivery of health care for the disadvantaged communities, namely the rural populations: women, children and the disabled. The Ministry of Health is the main healthcare provider in Malaysia. There has been much development in the healthcare system of Malaysia from the time of independence; starting from the development of the two-tier system and its subsequent transformation to a three-tier system, as well as the extension of healthcare delivery into rural areas in Sabah and Sarawak through the implementation of mobile teams and the Flying Doctor Service (FDS). The improvement in health status of the general population, particularly in rural settings is remarkable and in line with the Tenth Malaysian Plan on the road to Vision 2020. However, the current shift in disease burden from communicable to chronic non-communicable conditions continues to undermine these efforts. As a result, deficiencies in healthcare delivery and the health status of populations still exist, albeit more rampant in rural populations. We propose the implementation of Advanced Practice Nursing (APN) in the community as a solution to bridge gaps in health care provision in rural areas in line with Vision 2020. An advanced practice nurse is a specialty-specific registered nurse with an expert knowledge base and clinical competencies for extended practice. Modelled on Australian and Norwegian systems, advanced practice nurses are recruited directly from rural communities, with a better understanding of the population, and access to the local cultural norms, such as traditional healers. APN training is still in its infancy in many developing countries. Evidence from other similar models has proven that the care provided by specialised nurses results in higher patient satisfaction, greater access to health care, improved outcomes and cost effectiveness. APN compliment the care provided by physicians; reducing doctors' workload, patient waiting times and providing care in the convenience of the patients' homes. To succeed in improving health care outcomes by APN, the utilisation of evidence based practice, audits, guidelines, and escalation of specialist care at hospitals and continuous medical education are essential.

\section{Keywords}

Developing Countries, Sustainable, Community-Based Advanced Practice Nursing (APN) 


\section{Introduction}

Malaysia is a heterogenous, multi-ethnic nation with a population of 30 million as of 2014, consisting of Malays (50.1\%), Chinese (22.6\%), Indigenous (11.8\%), Indians (6.7\%) and other ethnic groups (8.9\%) [1]. It is also estimated that $26 \%$ of the total Malaysian population reside in rural areas [2].

\subsection{Development of the Malaysian Health System}

When Malaysia gained independence from the British occupation in 1957, healthcare services were predominantly found in urban areas. Each of the main states of the country had a State hospital, which was run by medical officers, paramedics and nurses; specialist care was scarce [3]. Rural healthcare services were practically non-existent. Members of the rural population thence mainly depended on traditional healers, Chinese medicine and traditional midwives for their health needs. In the 1960s, the Malaysian government embarked on an initiative to enhance the health status of its rural population, which brought about the First Malaysia Plan in 1966 paving the way to achieve Vision 2020 and the country's attempt to achieve "advanced nation" status by year 2020 [3]-[5]. In regards to health, it envisions that "An advanced nation is not solely about the income level, but also a good healthcare and social support system, the impact of which will be measurable through higher life expectancy and a superior standard of living. The benefits of these improvements shall be accessible to all members of the population regardless of income status" [4]. With this vision in mind, the healthcare system in the rural areas was established in tandem with the development of infrastructure such as roads, water supply and electricity in these underdeveloped areas [3].

By the early 1970s, before the declaration of the Alma Alta, primary and secondary health care were delivered via a three-tier system, with tertiary healthcare being confined to State hospitals. This three-tier system, demonstrated in Figure 1, consisted of a Main Health Centre, a Health Sub Centre and a Midwives Clinic [3]. The Main Health Centre was run mainly by medical officers, nurses, midwives, dentists, medical assistants and a public health team, catered for 50,000 populations and was in charge of 4 health sub-centres which consisted of a team of medical officers, nurses and midwives, catering for 10,000 populations. Each health sub-centre was in charge of 5 Midwives' Clinic which cared for 2000 populations. In 1973, the three-tier system was transformed into a two-tier system, as shown in Figure 1, with the upgrade of health sub-centres to main health centres (currently known as "klinik kesihatan" or health clinic), which cared for 20,000 populations, in order to enhance the



Figure 1. Transformation of healthcare delivery in Peninsular Malaysia. 
quality of care provided. Eventually, the midwives clinics were replaced with community clinics ("klinik desa") which cared for a population of 4000 . The community clinics were single-handedly run by community nurses ("jururawat masyarakat") and consulted doctors as and when necessary. They purely handled maternal and child health, and conducted regular home visits to ensure proper antenatal and postnatal care as well as family planning, immunization and developmental assessment of newborns [3].

The current population coverage of healthcare services is $95 \%$ in West Malaysian and $70 \%$ in East Malaysia. The provision of healthcare in Sabah and Sarawak has proven to be a major challenge due to the vast land area, of which 75\% still remains covered with dense forests [3] [4]. From the late 1970s to early 1980s, a network of health clinics run by paramedics and midwives were set up in East Malaysia to cater for 1500 to 3000 of the scattered rural populations. As depicted in Figure 2, the network was divided into 3 zones: immediate operational area (within $4.8 \mathrm{~km}$ to the health clinic), extended operational area (within $12 \mathrm{~km}$ to the health clinic) and outside extended operational area [3]. Those residing within the immediate operational zone were expected to come directly to the health centres. Those in the extended operational zones were attended to by mobile village health teams, consisting of medical officers and nurses, using boats. The Flying Doctor Service (FDS) was established in 1973 for those situated outside the extended operational zone. The FDS consists of a doctor, medical assistant and 2 community nurses who provide medical services to villages once a month using helicopters [3]. Considering the infrequency of the visits, a system of village health promoters came into play in 1981: Two volunteers from each village are trained in first aid and basic health services. They are then sent back to their respective villages with first aid kits and commonly used medications to provide and promote healthcare to the villagers under their care. This system has shown outstanding results as by the end of 2000. There were 2857 village health promoters from 1583 villages catering for approximately 262,368 people [3].

\subsection{Healthcare Reformation}

It is evident that Malaysia has a well-established health care system and is particularly exceptional in the region when considering accessibility of the public to primary health care services, all of which is in line with the Tenth Malaysian Plan, the five-year road map (2011-2015) of developmental strategies to achieve Vision 2020, which envisions "transforming health care to improve quality and provide universal access" [4] [5]. However, in this era of globalization, healthcare reformation is inevitable.

Health care reformation is a major policy creation or change in terms of healthcare delivery. Factors that make such a reformation in the healthcare system necessary are modernity, value changes, growth of the health market and most importantly, the change in the needs of the population in its care [4].

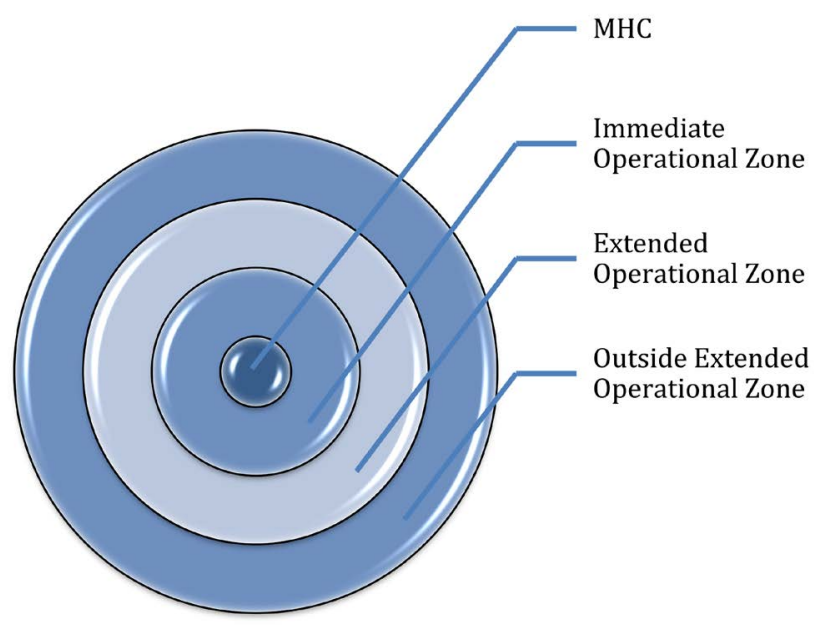

Figure 2. Healthcare delivery in Sabah and Sarawak. MHC: Main Health Center. Immediate Operational zone: within a $4.8 \mathrm{~km}$ radius, patients expected to come to clinic. Extended operational zone: within $12 \mathrm{~km}$ radius, served by Village Health Team. Outside Extended Operational Zone: $12 \mathrm{~km}$ radius, served by Flying Doctor Service (FDS). 
There has been a rise in the ageing population across the world, including Malaysia due to advances in healthcare services. However, increased life expectancy alongside economic prosperity and adoption of urban lifestyle which is more sedentary, has resulted in a shift of disease burden from communicable to non-communicable chronic conditions [14].

In order to further improve the quality and accessibility of health care services delivered to members of rural communities. It is our belief that training nurses in the holistic management of chronic conditions (i.e. Hypertension and Diabetes Mellitus) will greatly alleviate some of the burdens currently weighing on the health care system, and most importantly, it will help establish equal and equitable delivery of healthcare services.

This article will shed light on some of the factors that are currently contributing to the inequities in health care delivery. It will then go on to discuss models of care that have successfully implemented APNs to work effectively alongside physicians in both urban and rural settings. It will provide statistical evidence as to how this health reformation has succeeded in alleviating some of the inequities in health care systems of countries around the world. It will lastly cover how these models might have to be adapted to the different situations likely to be encountered in a developing country like Malaysia.

\section{Factors Contributing to Inequity of Health Care in Malaysia}

Figure 3 illustrates a framework comprising the factors impacting access to health care. Any solutions need to address the four components highlighted, including accessibility, availability, acceptability and affordability [6].

\subsection{The Current Misallocation of Health Care Professionals and How It Perpetuates Inequity}

Availability is the ability to attain sustainable health care as and when needed. It is heavily influenced by the number of doctors and nurses serving a population. Analysis of availability and health outcomes in different regions of the world has unsurprisingly proven the existence of a strong correlation between the two [7]. Regions of the world where health care professionals; doctors and nurses in particular, are in short supply suffer the worst health outcomes with high adult mortality rates and reduced life expectancies when compared to more developed regions like Europe (Table 1).

In poor countries, doctors and nurses tend to be concentrated in urban parts, with the rural regions being relatively neglected. India, for instance, has a worrying shortage of doctors and nurses; estimated ratios of doctors and nurses per 1000 are 0.7 and 0.9 respectively, as demonstrated in Figure 4 and Figure 5 [8]. In Australia, comparable ratios are as high as 3 and 10.1 . More importantly, only $25 \%$ of the total healthcare workforce provides for the rural communities of India, which constitute a majority of $72 \%$ of the total population [8].

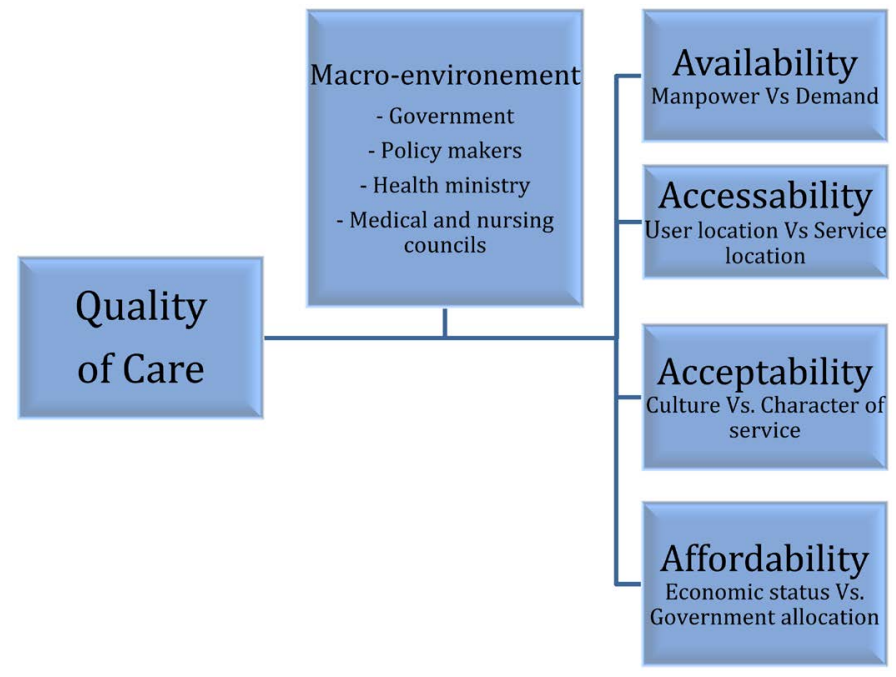

Figure 3. Conceptual Framework for assessing access to health services. Source: Poverty and Access to Health Care in Developing Countries [6]. 


\section{Doctors Per 1000 Population}

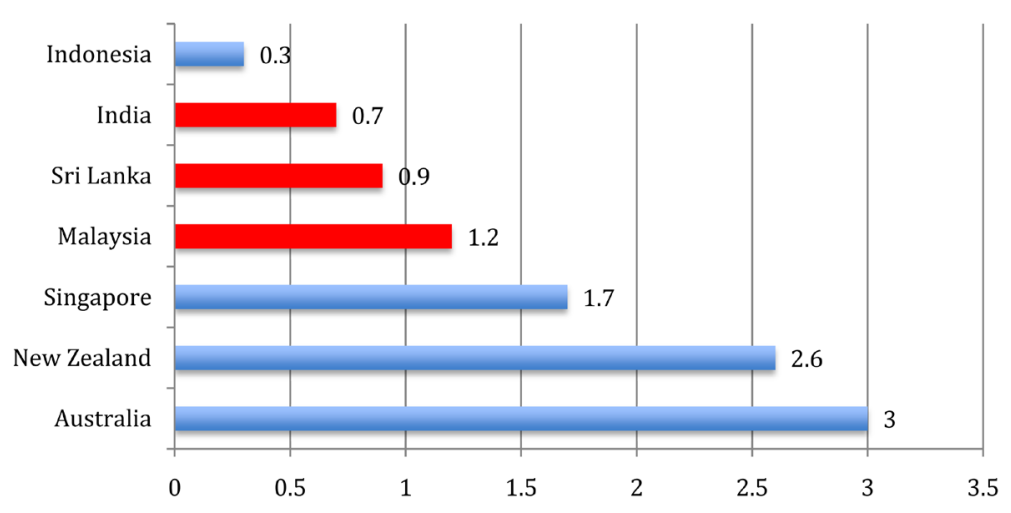

Figure 4. Doctors per 1000 population. Source: OECD health data 2012; WHO global health observatory data repository, national data sources [8].

\section{Nurses Per 1000 Population}

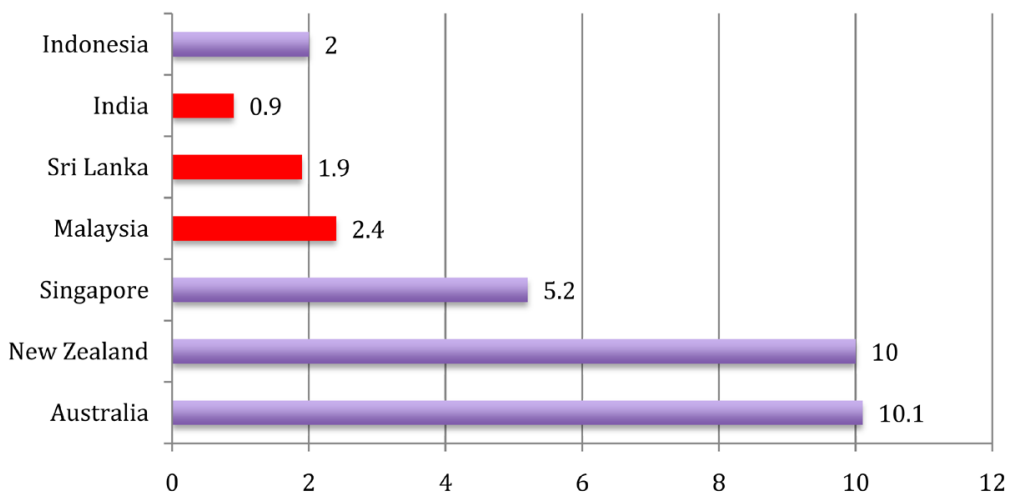

Figure 5. Nurses per 1000 populations. Source: OECD health data 2012; WHO global health observatory data repository, national data sources [8].

Table 1. Availability of Health Workforce, Life Expectancies and Adult Mortality Rates. Source: World Health Statistics 2010 [7].

\begin{tabular}{|c|c|c|c|c|}
\hline \multirow[t]{2}{*}{ Member State } & $\begin{array}{l}\text { Density of physicians } \\
\text { (per } 10,000 \text { population) }\end{array}$ & $\begin{array}{l}\text { Density of Nursing and } \\
\text { Midwifery Personnel (per } \\
10,000 \text { population) }\end{array}$ & $\begin{array}{l}\text { Life expectancy } \\
\text { at birth (years) }\end{array}$ & $\begin{array}{c}\text { Adult mortality rate } \\
\text { (below } 60 \text { years per } \\
1000 \text { population }\end{array}$ \\
\hline & 2000-2009 & 2000-2009 & 2008 & 2008 \\
\hline \multicolumn{5}{|c|}{ WHO REGION } \\
\hline Africa & 2 & 11 & 53 & 392 \\
\hline America & 23 & 55 & 76 & 126 \\
\hline South East Asia & 5 & 11 & 65 & 218 \\
\hline Europe & 33 & 68 & 75 & 149 \\
\hline Eastern Mediterranean & 10 & 14 & 65 & 203 \\
\hline Western Pacific & 14 & 21 & 75 & 113 \\
\hline \multicolumn{5}{|c|}{ INCOME GROUP } \\
\hline Low & 4 & 10 & 57 & 310 \\
\hline Lower Middle & 10 & 14 & 67 & 178 \\
\hline Upper Middle & 24 & 40 & 71 & 191 \\
\hline High & 28 & 81 & 80 & 87 \\
\hline
\end{tabular}


In Malaysia, which is a high income developing country, the ratio of physician per 1000 population is 1.2 . This is one-third of that found in more developed countries in the region, like Australia. The number of nurses per 1000 are similarly low, with countries like Malaysia and Sri Lanka having ratios almost 20\% of that seen in Australia and New Zealand in 2012, as demonstrated in Figure 5 [8].

Recruiting healthcare professionals to work in geographically isolated and resource poor settings always poses challenges, particularly as training tends to be based in well resourced city settings [9]. Additional factors include unattractive pay, lack of comparable education facilities for children, limited access to continuous medical education and social isolation from family and friends [10].

Hence, any strategy with the intention of ameliorating the inequities existent today in the Malaysian healthcare system must tackle the low availability of health care professionals in resource poor settings.

\subsection{The Current Nursing Profession and How It Perpetuates Inequity}

Figures support that the majority of the world's population is rural and yet only $38 \%$ of the total nursing workforce is allocated to serve them [9]. Shortage of frontline healthcare workers directly impacts healthcare delivery. Treatment cannot be monitored effectively, waiting times are longer and most importantly, patient education is not prioritised [9].

There has been recruitment of nurses from developing countries to cover for workforce shortages in higher income countries, which inflicts an economic loss to the countries that have invested in training these nurses. This feeds the workforce shortages in the countries needing healthcare workers, who are attracted by opportunity, improved living conditions and higher pay [9]. In Malaysia, a registered nurse's basic salary is averaged at RM2500 per month. In contrast, in the Middle East, a registered nurse earns RM8000 [11]. In more developed countries like the United States and the United Kingdom, a new graduate nurse earns around RM14,000 and RM8200 respectively [12]. Economic migration further widens the divide between inequitable supply of nurses in developed and developing countries.

There is increasing strain on provision of education for nurses with yet a large number of vacancies in nursing courses in developing countries [9]. This issue is further exaggerated by shortage of well-qualified nursing trainers; a main consequence of economic migration, and advanced age of educators, with a shrinking pool of younger nurses to replace them [9]. This has resulted in increased reliance on sessional trainers to account for these shortages in many parts of the developing world.

The curriculum designs adopted by most training programs cater for practice in high-end settings with advanced facilities [9]. For the healthcare workforce to possess the capacity to function effectively in rural communities, alterations to the current curricula of training programs need to be made to better suit rural settings. There is a need for increased training in management of non-communicable diseases and associated morbidity and complications.

\subsection{The Current Shift in Disease Pattern and How It Perpetuates Inequity}

Chronic non-communicable diseases such as diabetes, hypertension and ischaemic heart disease, which were once thought to be ailments of the affluent, are now severely impacting life expectancies of poorer populations. Unlike acute infectious diseases, non-communicable diseases require continuous expert management, which ideally should be available universally [13].

Many countries have experienced an increase in urban migration these past few decades, mainly for economic prosperity, employment and family reasons. According to the World Bank a dramatic drop in the rural population, from 50.2\% in 1990 to 27.8\% in 2008, has occurred in Malaysia [14]. In other countries, like Sri Lanka and India, though the percentage of urban populations has remained constant, overall numbers in the populations have increased. The adoption of urban lifestyles, which are more sedentary, increases the risks of developing life-style diseases such as obesity, hypertension, diabetes, hypercholesterolemia, chronic respiratory conditions along with their disabling complications.

Data from the Malaysian National Health and Morbidity Survey (NHMS) suggest a three-fold rise in the prevalence of obesity, from 4.4\% in 1996 to $15.1 \%$ in 2011 [15]. It is not surprising therefore that the prevalence of Type 2 diabetes also increased from 11.6\% in 2006, to 15.2\% in 2011. A similar picture is seen with other non-communicable diseases, such as hypertension and hypercholesterolemia affecting $35.1 \%$ and $32.7 \%$ of Malaysian adults in 2011 respectively [15], with a significant proportion of the population with these conditions 
being from rural areas.

A Global Burden of Disease Study conducted in 2013 [16] demonstrates a steep rise in the mortality rate caused by non-communicable diseases in both low and lower-middle income countries, whereas it shows a decline in those rates in high and upper middle income countries. By 2020, it is predicted that premature deaths caused by non-communicable diseases in low-income countries are to reach even higher rates with significant impact on the economy consequent to reduction in the workforce [16]. These astounding results were obtained from the Institute of Health Metrics and Evaluation and has been presented in Figure 6.

This dichotomy in trend of mortality, despite the high prevalence of non-communicable diseases in developed regions, as tabulated in Table 2, is attributable to high quality health care systems with sufficient manpower for optimal management and follow up of these conditions in the developed world, whilst big portions of populations of low-income countries are denied this privilege.

In view of the low availability of health care professionals, their unjust allocation, shortcomings of the nursing profession and the changing trend of disease burden towards non-communicable diseases in developing countries, these countries have to take cost-effective measures to tackle these issues simultaneously. We propose

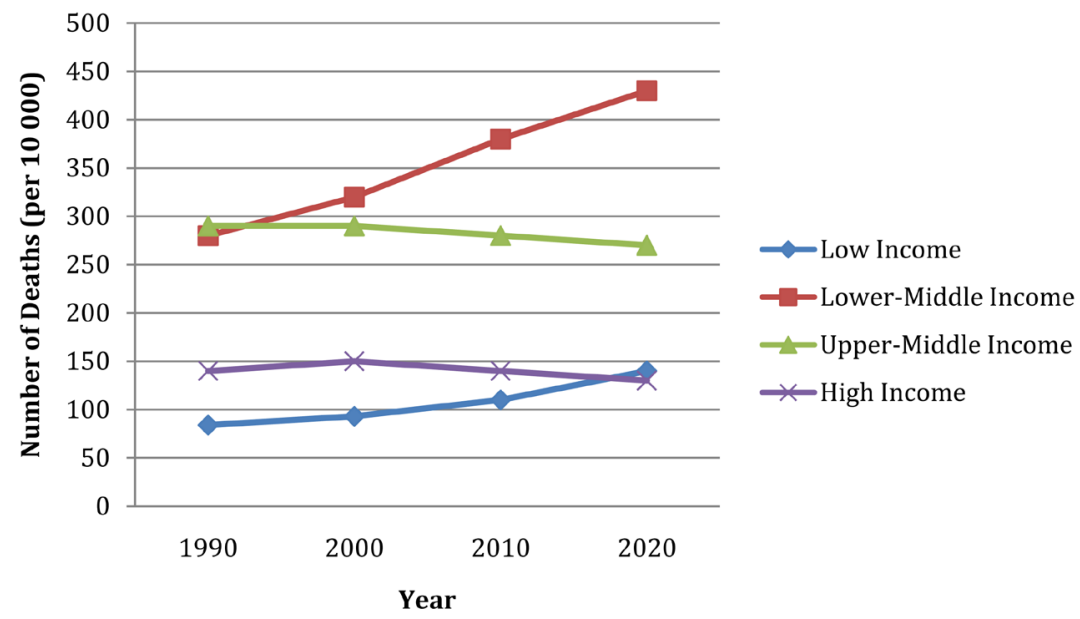

Figure 6. Premature (Under age sixty) deaths caused by all non-communicable diseases. Source: Institute for health metrics and evaluation, global burden of disease study 2013 [16].

Table 2. Life expectancies and adult mortality rates. Source: World health statistics 2010 [7].

\begin{tabular}{ccc}
\hline \multirow{2}{*}{ Member State } & Cause-Specific mortality (per 100,000 population) \\
\cline { 2 - 3 } & CD & NCD \\
Africa & 978 & \\
America & 91 & 841 \\
South East Asia & 363 & 499 \\
European & 62 & 701 \\
Eastern Mediterranean & 308 & 590 \\
Western Pacific & 99 & 790 \\
& Income group & 557 \\
Low & 515 & 794 \\
Lower Middle & 125 & 675 \\
Upper Middle & 97 & 692 \\
High & 32 & 408 \\
\hline
\end{tabular}


the implementation of APN as an initiative solution to these problems. Due to the new trend in disease burden, we propose that these nurses be trained in the management of chronic non-communicable conditions. We strongly believe that this will not only cost-effectively increase the manpower of health care available to serve the population, but also will help amend some of the deficiencies in the nursing profession.

\section{Advanced Practice Nursing (APN)}

\subsection{Definitions and Job Scope}

An Advanced Practice Nurse is a Registered Nurse (RN) who has acquired the expert knowledge base, complex decision-making skills and clinical competencies for extended practice [17]. Advanced Practice Nurses are required to complete disease-specific graduate programs that include education, training, and practical experience following their undergraduate programs, in order to complete a national board certification examination before entry into practice [18]. The job scope of an Advanced Practice Nurse is more extensive than that of a basic registered nurse covering more aspects of clinical practice. The additional disease-specific training Advanced Practice Nurses receive offers them a certain skill-set to practice, with greater autonomy, complex nursing care which allows for more holistic management of their patients' clinical conditions. Furthermore, they rank higher on the nursing hierarchy. Their role largely depends on what category they belong to. Nurse Practictioners, for instance, can diagnose and treat common conditions, and therefore have the capacity to function as the main healthcare providers for a number of patients. A Clinical Nurse Specialist on the other hand functions as an expert, and their opinion is sought when a more specialized care is mandated. Since this manuscript focuses on providing more holistic management of chronic illnesses like hypertension, diabetes, ischaemic heart disease, stroke, malignancies and chronic respiratory syndromes in rural settings in Malaysia, both categories of advanced practice nursing should be implemented, with the emphasis of placing them in Community Clinics.

Based on the global characteristics of the APN Role published by the International Council of Nursing in 2013, an Advanced Practice Nurse's authority encompasses more extensive management of patients within their field of specialty. However, it is essential that clinically competent physicians support, educate and guide Advanced Practice Nurses in the community. Advanced Practice Nurses, therefore, need to work collaboratively with physicians in an appropriate environment on regular intervals in multidisciplinary clinics/hospital settings in order to gain confidence to ensure appropriate management [19] [20]. Advanced Practice Nurses need access to clinical guidelines and protocols with regular audits, to ensure standards and quality of care are being met. As part of research, consumer engagement with patient and professional satisfaction surveys are essential. These measures will ensure retention, job satisfaction and prevent isolation.

\begin{tabular}{l} 
Global Characteristics of the APN Role \\
\hline Right to suspect diagnosis \\
Authority to prescribe medication (for conditions within their field of specialty) \\
Authority to prescribe treatment (for conditions within their field of specialty) \\
Authority to refer clients to other professionals \\
Authority to admit patients to hospital (for conditions within their field of specialty) \\
Legislation to confer and protect the title "Nurse Practitioner/Advanced Practice Nurse" \\
Legislation or some other form of regulatory mechanism specific to advanced practice nurses \\
Officially recognized titles for nurses working in advanced practice roles \\
\hline
\end{tabular}

International council of nursing 2013 [21].

The role of Advanced Practice Nurses in a healthcare system to improve its efficiency and cost effectiveness has been successfully implemented in different parts of the world. Research reviewing the roles of Advanced Practice Nurses dates back to the 1970s and 1980s in countries like the UK and the US. Although the concept of APN is still in its infancy in the developing world, programs built on similar principles are currently existent in Malaysia, this includes mainly the community nursing programs for maternal and child health mentioned earlier. However, these maternal and child health programs are not officially recognised as APN programs. We propose that in addition to implementing APN programs for the management of chronic non-communicable diseases, legislative and policy reforms ensure official recognition of already existent programs as APN programs by the 
Nursing Councils and the Ministry of Health, and that nurses working within the confinements of such programs be upgraded to Advanced Practice Nurses status through further education and training. For the development and implementation of APN to be effective in the population, it is imperative that lessons from international experiences with such programs are undertaken. Alongside modifications to meet the demands of different populations, these reforms will be successful in providing sustainable high quality care.

\subsection{Recruitment of Nursing (Australian and Norwegian Models)}

There has been an international emphasis on recruiting health care professionals from rural communities to increase the likelihood of sustaining rural practice and workforce. Such interventions in recruitment policies have been successfully adopted by the Australian and Norwegian healthcare systems to recruit and retain physicians in rural areas [22]-[25].

The "Rural Pipeline Template" is a concept first adopted in the United States, endorsed by Fisher and Fraser in Australia [26] [27]:

"The key seems to be the creation of a pipeline that reaches out to rural communities to encourage the selection and success of rural students, gives them opportunities throughout medical school and residency to work in rural settings, and supports them in practice after they do settle in rural areas".

This concept was initially developed in an attempt to widen the pool of physicians that would eventually take up careers in rural settings. Fisher and Fraser in Australia proposed extending this concept to nursing programs in order to increase their numbers in rural populations [27] [28].

There needs to be recognition that students from rural areas tend to be disadvantaged when compared to their urban counterparts in gaining access to higher education. Positive discrimination including interventions such as lowering entry requirements could help increase the pool of young students entering nursing. There also needs to be recognition that increasing exposure of nursing students to rural experiences forms part of the core curriculum of the undergraduate course. Measures should address retention of those professionals within the communities they choose to serve upon completion of training [27].

Studies that analysed the effectiveness of the "Pipeline Template" concluded that previous residency in rural communities was the strongest predictor of continuing with a rural career, as well as extended rural exposure during undergraduate training. This choice is also influenced significantly by robust professional support at a local, state and national level, availability of career progression, willingness of family members to adopt a rural lifestyle, adequate educational facilities for children and geographical proximity to extended family and friends [28]. This work provides a deeper insight into the factors influencing choice.

Decentralizing Nursing Education (DNE) is another concept adopted by the Norwegian health care system. It similarly involves the recruitment of students from their respective rural areas, and training them in locations away from urban centres nearer to their communities [22]. This is based on the assumption that once the nurses graduate, they are more likely to return and practice in their own rural communities.

Results obtained from studies analysing the effectiveness of DNE in rural areas of Norway showed nurses remained in those areas for a median of 30 years, proving that this reform has succeeded in providing long term solutions to the low numbers of nurses serving rural societies. The DNE provided nurses with the capacity to effectively balance time to both their family and educational responsibilities. This was achieved with a 4-year extended training program offering nursing students higher education within their own communities, negating travel away from home and family [29].

Based on the success rates these two models have achieved, we propose that more nursing students are recruited from rural communities, trained in centres close to their own rural communities, with sufficient exposure to rural practices during their training years. As for curricula, sufficient understanding of the epidemiology of disease in a specific community is of utmost importance as training should be tailored to the needs of the communities these nurses will provide for after graduation. This will ensure cost-effectiveness in the provision of a sustainable high-quality health care to marginalised and disadvantaged communities.

\subsection{Benefits of Advanced Practice Nursing (APN)}

\subsubsection{Improved Health Outcomes}

A systematic review of literature published between 1990 and 2008 conducted in the US shows that the quality of health care delivered by Advanced Practice Nurses in collaboration with physicians is superior in many aspects 
to the health care delivered by physicians alone [17]. The evidence not only demonstrates that the role of Advanced Practice Nurses in healthcare delivery significantly improves its outcomes but also improves patients' levels of satisfaction and perceived health [17] [30].

Better control of health parameters including blood glucose, blood pressure and lipid profiles in patients attended to by Advanced Practice Nurses compared to those attended by physicians alone has been noted [17] [30]. More effective management of chronic conditions has reduced complications, disability and frequency of ED visits and hospital admissions, thus reducing significantly the cost borne by the healthcare system [17].

\subsubsection{Improved Attractiveness of Nursing as a Profession}

Many young students in many countries perceive nursing as an unattractive job [9]. APN will improve the attractiveness of the nursing profession by enhancing career progression, prospects and job satisfaction. The introduction of APN is also likely to improve rural retention rates. Fundamental to rural retention is job satisfaction, which in turn is heavily influenced by a sense of authority, greater autonomy and flexibility in practice among nurses [31], prospects that APN provides.

\subsubsection{Cost of Training}

A medical MBBS degree in Malaysia takes a minimum of 5 years to complete with an estimated cost of RM 455,000, in comparison a 3-year basic nursing program costs approximately RM 60,000 [32]. A further two years of in-service training will cost RM 25,000, putting the total cost of an Advanced Practice Nurse at one fifth that of training a Doctor [32] [33]. A potential model for developing countries to meet the increasing demands on their health care systems is to place greater emphasis on widening the pool of registered nurses with more opportunities to pursue further specialisation to become Advanced Practice Nurses, alongside increased remuneration and recognition [34].

\subsection{Pitfalls of APN}

Despite the long evolutionary chain of APN, its rapid adoption and integration into health care systems of many countries has brought with it a great sense of ambiguity in regards to the definition and accurate description of job scope of the different types of advanced practice nurses [21]. This has been identified as a hurdle for nurses working within an APN environment [20]. The health parameters within which a nurse can practice, and thus contribution to health care has to be clarified to nurses as well as other allied health care professionals to raise awareness among nurses themselves as to what exactly their training and experience entitle, and to better inform other health care professionals, mainly doctors, of the new emerging role of APN.

\subsection{Obstacles Facing the Successful Implementation of Advanced Practice Nursing (APN)}

Circumstances differ among countries. The geography, proportion of populations living in isolated locations, and the prevalence of diseases are all factors that shape the nature of potential obstacles likely to face the implementation of APN. Adoption of such a change is likely to be easier in a relatively smaller country like Malaysia where $72 \%$ of the population lives in urban areas whereas much hardship is likely to be faced in a larger country like India, where $82 \%$ of the population lives in rural areas [2] [9].

In addition, in developing countries, rural populations tend to rely more heavily on traditional medicine and healers because of their cultural beliefs. Unless there is a better understanding of these beliefs, provision of modern medical care faces challenges to the acceptance of the populations being served

Introducing APN into the health care system of a developing country like Malaysia comprises a great change to the very foundations of the nursing profession, a change whose ripple effect extends beyond nurses, and impacts allied health care professionals, namely doctors, equally. The extensive training that Advanced Practice Nurses receive gives them the capacity to perform medical and surgical procedures that are traditionally performed by physicians alone. This may be seen by some physicians as invasion of jurisdiction. This has been documented in Nigeria where the extensive skill set of Advanced Practice Nurses created some degree of hostility between doctors and nurses [30].

Studies analysing patients' safety when Advanced Practice Nurses were the primary health care providers have concluded that it is entirely safe given that Advanced Practice Nurses provide for patients within their field of specialty. Despite this, legislative bodies and policy makers of countries where APN has been implemented 
still impose stringent laws on the flexibility of practice of Advanced Practice Nurses, and dictate that "supervision", rather than "collaboration", shall be the mode of interaction between Advanced Practice Nurses and physicians [35] [36]. This is seen by many as an impediment to the fostering of quality competition that is of benefit to consumers.

\section{Conclusions}

Implementation of APN for the provision of high quality healthcare in both urban and rural settings of Malaysia is a promising step towards the realisation of Vision 2020, which envisions "Universal access to high quality healthcare". Various models and frameworks for the implementation of such a change can be adopted, with modifications to ensure suitability to the local needs. Training of Advanced Practice Nurses in the holistic management of chronic conditions such as Diabetes Mellitus and Hypertension should be our priority in order to tackle the changing trend of disease. Such a fundamental reformation in the way health care is delivered is likely to be faced by many obstacles and scepticism, and it is therefore the duty of administrative bodies such as the Ministry of Health (MOH) and the Nursing Counsels to overcome these obstacles by clearly defining APNs and their job scope. APN is likely to benefit not only the populations served, but the health care system and the entire nation in general.

Although the main focus of this article was the implementation of APN in rural communities, its implementation in urban ones should also be the aim of health policy makers, as it is anticipated to be much easier, with similar benefits to the urban populations and the healthcare system in general.

\section{References}

[1] Barrientos, M. and Soria, C. (2014) Malaysia Demographics Profile. http://www.indexmundi.com/malaysia/demographics profile.html

[2] World Development Indicators (accessed 12 March 2015) Urban Population Growth. http://data.worldbank.org/indicator/SP.URB.TOTL.IN.ZS

[3] Tens, C.L. and Ariff, K.M. (2002) Rural Health Care in Malaysia. Australian Journal of Rural Health, 10, 99-103. https://www.researchgate.net/publication/11325060 Rural health care in Malaysia.

[4] Mercian, M.I., Rohaizat, Y. and Haniza, S. (2004) Developing the Malaysian Health System to Meet the Challenges of the Future. Medical Journal of Malaysia, 59, 84-93. http://www.e-mjm.org/2004/v59n1/Malaysian Health System.pdf

[5] Martin, L.A., Neumann, C.W., Mountford, J., Bisognano, M. and Nolan, T.W. (2009) Increasing Efficiency and Enhancing Value in Health Care: Ways to Achieve Savings in Operating Costs per Year. IHI Innovation Series White Paper. Institute for Healthcare Improvement, Cambridge, MA. (Available on www.IHI.org)

[6] David, H.P., Garg, A., Bloom, G., Walker, D.G., Breiger, W.R. and Rahman, M.H. (2008) Poverty and Access to Health Care in Developing Countries. Annals of the New York Academy of Sciences, 1136, 161-171. http://onlinelibrary.wiley.com/doi/10.1196/annals.1425.011/full

[7] WHO (2009) WHO Global Database on Maternal Health Indicators, 2009 Update. World Health Organization, Geneva. www.who.int/reproductive-health/global_monitoring/index.html

[8] OECD/WHO (2012) Health at a Glance: Asia/Pacific 2012. OECD Publishing, Paris. http://dx.doi.org/10.1787/9789264183902-en

[9] World Health Organisation (WHO) (2010) Wanted: 2.4 Million Nurses, and That's Just in India. Bulletin of the World Health Organisation, 88, 321-400. http://www.who.int/bulletin/volumes/88/5/10-020510/en/

[10] Dark, E.K., Newman, M.S., Kawkab, M. and Chowdhury, M.E. (2015) A Qualitative Study of Factors Influencing Retention of Doctors and Nurses at Rural Healthcare Facilities in Bangladesh. BMC Health Services Research, 15, 344. http://bmchealthservres.biomedcentral.com/articles/10.1186/s12913-015-1012-z http://dx.doi.org/10.1186/s12913-015-1012-z

[11] Borneo Post Online. High Salaries Await Registered Nurses Abroad. http://www.theborneopost.com/2012/11/21/high-salaries-await-registered-nurses-abroad/\#ixzz3YENiwIQD

[12] Health Care Salaries. Average Nurse Salary. http://www.healthcare-salaries.com/nursing/average-nurse-salary

[13] Schieber, G. and Maeda, A. (1999) Health Care Financing and Delivery in Developing Countries Health Affairs, 18, 193-205. http://dx.doi.org/10.1377/hlthaff.18.3.193

[14] Trading Economics. Urban Population (\% of Total) in Malaysia. http://www.tradingeconomics.com/malaysia/urban-population-percent-of-total-wb-data.html 
[15] Tahir, A. and Ani, N. (2012) Malaysian National Health and Morbidity Survey 2011. Institute of Public Health. Kuala Lumpur.

[16] Institute for Health Metrics and Evaluation, Global Burden of Disease Study (2013) The Emerging Crisis: Noncommunicable Diseases. http://www.cfr.org/diseases-noncommunicable/NCDs-interactive/p33802?cid=otr-marketing_use-NCDs_interactive/\#!/

[17] Newhouse, R.P., Stanik-Hutt, J., White, K.M., Johantgen, M., Bass, E.B., Zangaro, G., et al. (2011) Advanced Practice Nurse Outcome 1990-2008: A Systematic Review. Nursing Economics, 29, 230-250.

[18] Nerminathan, V., Adlan, W. and Nerminathan, A. (2014) Hospital at Home: Sustainable Healthcare in Developing Countries through Reducing Average Length of Stay in Hospitals. International Journal of Management and Sustainability, 3, 51-61.

[19] Singapore Nursing Board. Advanced Practice Nurse. Singapore Nursing Board, Singapore. http://www.healthprofessionals.gov.sg/content/hprof/snb/en/leftnav/advanced_practice_nurse.html

[20] Gardner, G., Chang, A. and Duffield, C. (2006) Making Nursing Work: Breaking through the Role of Confusion of Advanced Practice Nursing. Journal pf Advanced Nursing, 57, 382-391. http://dx.doi.org/10.1111/j.1365-2648.2007.04114.x

[21] Kleinpell, R., Scanlon, A., Hibbert, D., Ganz, F., East, L., Fraser, D., Wong, F. and Beauchesne, M. (2014) Addressing Issues Impacting Advanced Nursing Practice Worldwide. The Online Journal of Issues in Nursing, 19, 4.

[22] Princeton, J.C. and McGrath, B.J. (1989) Decentralized Nursing Education: Does It Work? The Journal of Continuing Education in Nursing, 20, 54-57.

[23] Alexandersen, Ø., Jørgensen, E., Østerås, J. and Hasvold, T. (2004) Medisinerutdanningen i Tromsø—Sikrer den legerekrutteringen I Nord-Norge? (Medical Education in Tromsø-Does It Secure the Recruitment of Doctors in North Norway). Tidsskrift for den Norske Læegeforening, 124, 2107-2109. (In Norwegian)

[24] Cleland, J., Johnston, P.W., Walker, L. and Needham, G. (2012) Attracting Healthcare Professionals to Remote and Rural medicine: Learning from Doctors in Training in the North of Scotland. Medical Teacher, 34, e476-e482. http://dx.doi.org/10.3109/0142159x.2012.668635

[25] Gaski, M., Abelsen, B. and Hasvold, T. (2008) Forty Years of Allocated Seats for Sami Medical Students-Has Preferential Admission Worked? Rural and Remote Health, 8, 845.

[26] Fisher, K.A. and Fraser, J.D. (2010) Rural Health Career Pathways: Research Themes in Recruitment and Retention. Australian Health Review, 34, 292-296. http://dx.doi.org/10.1071/AH09751

[27] Council on Graduate Medical Education (1998) Tenth Report, Physician Distribution and Health Care Challenges in Rural and Inner-City Areas. CGME, Rockville, 23.

[28] Playford, D., Wheatland, B. and Larson, A. (2010) Does Teaching an Entire Nursing Degree Rurally Have More Workforce Impact than Rural Placements? Contemporary Nurse, 35, 68-76. http://dx.doi.org/10.5172/conu.2010.35.1.068

[29] Andersen, A. (1989) Desentralisert sykepleierutdannning organisert som deltidsutdanning (Decentralized Nursing Education Organized as Part-Time Education). Report, Tromsø University College, Tromsø, Norway. (In Norwegian)

[30] Ugochukwu, C.G., Nnabuenyi, A.I. and Ndubuka, C.C. (2015) Advanced Practice Nursing Challenges in Developing Countries: Perception of Nurses in Selected Health Care Facilities in South East Nigeria. In: Nurses and Midwives: Agents of Change, Commonwealth Nurses Federation, London. http://www.commonwealthnurses.org/conference2014/Documents/ChikaUgochukwu.pdf

[31] Manahan-Roberge, C. and Lavoie, J.G. (2008) Who Stays in Rural Practice? An International Review of the Literature on Factors Influencing Rural Nurse Retention. Online Journal of Rural Nursing \& Health Care, 8, 42-53.

[32] International Medical University (IMU). Application and Registration Fees. http://www.imu.edu.my/imu/programmes/undergraduate/nursing/

[33] International Medical University (IMU). Application and Registration Fees. http://www.imu.edu.my/imu/programmes/undergraduate/medicine/

[34] Fagerström, L. (2012) The Impact of Advanced Practice Nursing in Healthcare: Recipe for Developing Countries. Annals of Neurosciences, 19, 1-2. http://www.ncbi.nlm.nih.gov/pmc/articles/PMC4117071/ http://dx.doi.org/10.5214/ans.0972.7531.180401

[35] American Academy of Family Physicians (2012) Primary Care for the 21st Century: Ensuring a Quality, Physician-Led Team for Every Patient.

http://www.aafp.org/dam/AAFP/documents/about_us/initiatives/AAFP-PCMHWhitePaper.pdf?cmpid=npp12_ad_com _na_van_1

[36] Gilman, D.J. and Koslov, T.I. (2014) Policy Perspectives: Competition and the Regulation of Advanced Practice Nurses. Federal Trade Commission.

https://www.ftc.gov/reports/policy-perspectives-competition-regulation-advanced-practice-nurses 